\title{
Transient stability enhancement using thyristor controlled series compensator
}

\author{
Surender Reddy Salkuti \\ Department of Railroad and Electrical Engineering, Woosong University, Republic of Korea
}

\begin{tabular}{l}
\hline \hline Article Info \\
\hline Article history: \\
Received May 27, 2018 \\
Revised Nov 10, 2018 \\
Accepted Dec 8, 2018 \\
\hline
\end{tabular}

\section{Keywords:}

FACTS devices

Stability margin

TCSC

Transient stability

\begin{abstract}
Stability is an important issue which determines the stable operation of power system. At present, the most practical available method of transient stability analysis is time domain simulation, in which the non-linear differential equations are solved by step by step method or network reduction techniques. In this paper, FACTS devices are used in the existing system for effective utilization of existing transmission resources. In this paper, the studies have been carried out in order to improve the transient stability of 5 bus system, and Western System Coordinating Council (WSCC) 9 bus system with fixed compensation on various lines, and the optimal location has been investigated for better results. To improve the transient stability margin further, a Thyristor Controlled Series Compensator (TCSC) has been used, and the results shows the effectiveness of the application of TCSC in improving the transient stability of power system.
\end{abstract}

Copyright $@ 2019$ Institute of Advanced Engineering and Science. All rights reserved.

\section{Corresponding Author:}

Surender Reddy Salkuti,

Department of Railroad and Electrical Engineering,

Woosong University,

Jayang-dong, Dong-gu, Daejeon-300718, Republic of Korea.

Email: surender@wsu.ac.kr

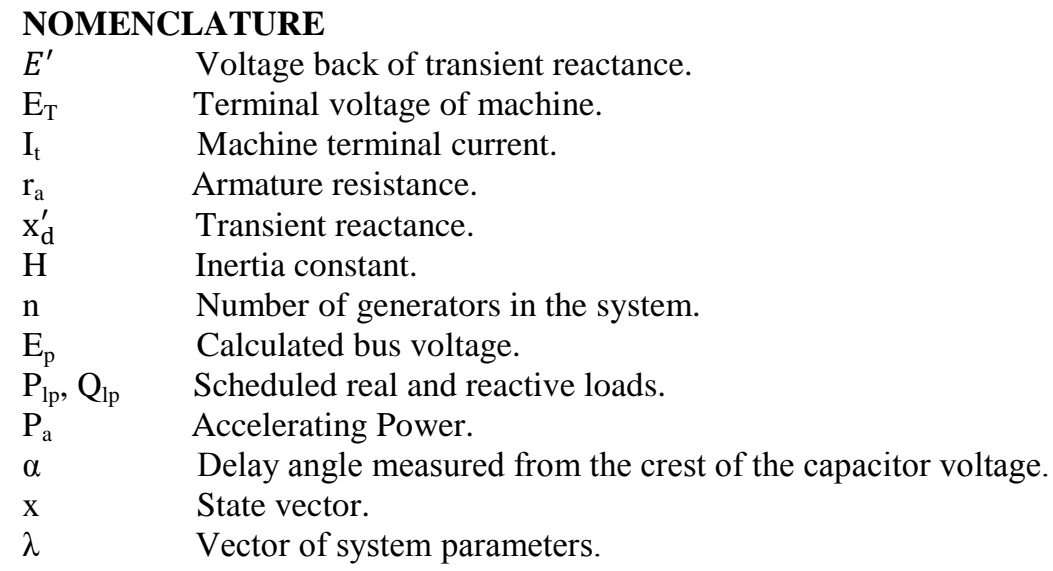

\section{INTRODUCTION}

Power systems have Background: Power system stability is an important issue for the secure system operation. As evolved through continuing growth in interconnections, use of new technologies and controls, and the increased operation in highly stressed conditions, different forms of system instability have emerged. A clear understanding of different types of instability, and how they are interrelated is essential for the 
satisfactory design and operation of power systems. Power system stability is the ability of an electric power system, for a given initial operating condition, to regain a state of operating equilibrium after being subjected to a physical disturbance, with most system variables bounded, so that practically the entire system remains intact [1].

The Problem: During the steady state operation, Thyristor Controlled Series Capacitor (TCSC) helps in controlling and increasing the power flow through a transmission line. Another important aspect of TCSC is that, its use during the large disturbances like faults, because of their capability to improve the transient stability of power system. A study of effects of a TCSC on the variation of transient stability condition of a power system including both the network and the generators, have been simulated in [2]. Reference [3] presents the variable effective fundamental equivalent reactance capability of TCSC for enhancing the transient stability of power systems. For obtaining the varying effective fundamental equivalent reactance, two different controllers i.e., a speed deviation based self-tuning Fuzzy Proportional Integral Derivative (PID) controller, and a non-linear controller are used. Different control aspects related to the use of TCSC for the stability improvement of power systems are addressed in [4]. In [5], an overview to the general types of FACTS controllers is given along with the simulation of TCSC using Simulink. Reference [6] presents the effects of TCSC on transient stability improvement of the Single Machine Infinite Bus system with the consideration of resistance of the transmission line. In order to improve the transient stability margin, a series FACTS device has been implemented, and the advantage of the use of TCSC with a fuzzy controller over fixed capacitor operation is presented in [7].

An automatic FACTS device allocation process based on evolutionary algorithm to enhance the voltage stability of power systems is proposed in Reference [8]. In Reference [9], a multi-objective framework is proposed for congestion management where three competing objective functions including total operating cost, voltage and transient stability margins are optimized simultaneously. A local fuzzy based damping controller for TCSC to improve transient stability of power systems is proposed in [10]. In Reference [11], the power system stability including the effects of FACTS controllers is proposed. A procedure for modelling and optimal tuning the parameters of TCSC controller for the power system transient stability is proposed in Reference [12]. Reference [13] proposes the use of specific FACTS devices and WAMS systems to maximize total transfer capability generally defined as the maximum power transfer transaction in Central-East-Europe power system. The application of Multi-Objective Genetic Algorithm to solve the Voltage Stability Constrained Optimal Power Flow problem is proposed in [14]. A mathematical derivation for the voltage dependency of a Controllable Series Compensator and a Static Synchronous Series Compensator in a single-load infinitive-bus model is proposed in Reference [15].

The Proposed Solution: In order to improve the Transient Stability (TS) margin, a series FACTS device has been implemented in this paper. A fuzzy controlled TCSC has been used, and the results highlight the effectiveness of the proposed approach in improving the transient stability of a power system. The Trajectory Sensitivity Analysis (TSA) has been used to measure the transient stability condition of the system. The TCSC is modeled by a variable capacitor, the value of which changes with the firing angle. It is shown that TSA can be used in the design of the controller. The optimal locations of the TCSC controller for different fault conditions can also be identified with the help of TSA. The studies have been carried out in order to improve the Transient Stability (TS) of WSCC 3 machine 9 bus system. This paper depicts the advantage of the use of proposed approach by using the TCSC.

The remainder of the paper is organized as follows: Section 2 describe about the transient stability analysis and the modeling of the system. Section 3 presents the transient stability of multi-machine system. The modeling of TCSC and power system is presented in Section 4. The trajectory sensitivity analysis is presented in Section 5. Section 6 presents results and discussion. Finally, Section 7 brings out contributions with concluding remarks.

\section{TRANSIENT STABILITY ANALYSIS}

The transient stability studies provide information related to the capability of power system to remain in synchronism during major disturbances resulting from either the loss of generation or transmission facilities, sudden or sustained load changes, or momentary faults. Specifically, these studies provide the changes in voltages, currents, powers, speeds, and torques of machines of power system, as well as the changes in system voltages and power flows, during and immediately following a disturbance. Transient stability analysis is performed by combining the solution of algebraic equations describing the network with numerical solution of differential Equations [16]. The solution of the network equations retains the identity of the system, and thereby provides access to system voltages and currents during the transient period. Modeling of the system is presented next: 


\subsection{Synchronous machine model}

The synchronous machine is represented by a voltage source, in back of a transient reactance, that is constant in magnitude, but changes in angular position. If the rotational power losses of the machine due to such effects as windage and friction are ignored, then the accelerating power equals the difference between mechanical and electrical power [6]. The classical model can be described by the following set of differential and algebraic equations:

Differential Equations:

$$
\begin{aligned}
& \frac{d \delta}{d t}=\omega-2 \pi f \\
& \frac{d^{2} \delta}{d t^{2}}=\frac{d \omega}{d t}=\frac{\pi f}{H}\left(P_{m}-P_{e}\right)
\end{aligned}
$$

Algebraic Equations:

$$
E^{\prime}=E_{T}+r_{a} I_{t}+j x_{d}^{\prime} I_{t}
$$

\subsection{Representation of loads}

Power system loads, other than motors are represented by equivalent circuits, and can be treated in several ways during the transient period. The commonly used representations are either static impedance or admittance to ground, constant real and reactive power, or a combination of these representations [17]. The parameters associated with static impedance and constant current representations are obtained from the scheduled bus loads. The bus voltages are calculated from a load flow solution for the power system prior to a disturbance [5]. The initial value of the current for a constant current representation is obtained from the following equation,

$$
I_{p o}=\frac{P_{l p}-j Q_{l p}}{E_{p}^{*}}
$$

The static admittance (Ypo) is used to represent the load at bus P, and can be obtained from [18],

$$
Y_{p o}=\frac{I_{p o}}{E_{p}}
$$

The diagonal elements of admittance matrix (YBus) corresponding to the load bus are modified using Ypo.

\subsection{Simulation of faults}

A fault at or near a bus is simulated by appropriately changing the self-admittance of the bus. For a three-phase fault, the fault impedance is zero, and the faulted bus has the same potential as the ground. This involves placing infinite shunt admittance, so that the bus voltage is in effect zero. The fault is removed by restoring the shunt admittance to the appropriate value depending on the post-fault system configuration.

\subsection{Single machine connected to an infinite bus}

The transient stability pertains to the stability under large disturbances. Hence, the non-linear ties of the model have to be considered in the analysis. As analytical solutions are not available for the swing equation, numerical methods have to be used.

\section{TRANSIENT STABILITY OF MULTI-MACHINE POWER SYSTEM}

The procedure for determining the stability of multi-machine system is described next:

Step 1: From the pre-fault load flow data, determine $E_{k}^{\prime}$ (voltage behind transient reactance) for all generators. This establishes generator emf magnitudes $\left|E_{k}\right|$, which remains constant during the study, and initial rotor angle $\delta_{k}^{0}=$ angle of $\left(E_{k}\right)$. Also, record prime mover inputs to generators, $P_{m k}=P_{g k}^{0}$.

Step 2: Augument the load flow network by the generator transient reactances. Shift network buses behind the transient reactances.

Step 3: Find $Y_{\text {bus }}$ for various network conditions: during fault, post fault (faulted line cleared), after line reclosure. 
Step 4: For faulted mode, find generator outputs from power angle equations, and solve the swing equations by using the step by step/point by point method or any integration algorithms such as modified Euler's method, Runga Kutta fourth order method, etc.

Step 5: Keep repeating the above step for post-fault mode and after line reclosure mode.

Step 6: Examine $\delta(\mathrm{t})$ plots for all the generators, and establish the answer to the stability question.

\subsection{Algorithm for network reduction technique}

To prepare the system data for stability study, the following preliminary calculations are required:

a) All system data are converted to a common base.

b) The loads are converted to equivalent impedances or admittances. The needed data for this step are obtained from the load flow study [19]. Therefore, if a certain load bus has a voltage VL, power PL, reactive power QL, and current IL flowing into the load admittance $\mathrm{YL}=\mathrm{GL}+\mathrm{jBL}$, then,

$$
P_{L}+j Q_{L}=V_{L} I_{L}^{*}=V_{L}^{2}\left(G_{L}-j B_{L}\right)
$$

The equivalent shunt admittance at that bus is given by,

$\mathrm{YL}=\mathrm{PL} / \mathrm{VL} 2-\mathrm{j}(\mathrm{QL} / \mathrm{VL} 2)$

c) The internal voltages of the generators $\operatorname{Ei}\left\llcorner\delta_{i}^{0}\right.$ are calculated from the load flow data. These internal angles may be computed from the pre-transient terminal voltages $V\llcorner\alpha$ as follows:

Let the terminal voltage be used temporarily as a reference. If we define $I=I 1+j \mathrm{I} 2$, then from the relation $\mathrm{P}+\mathrm{jQ}=\mathrm{VI}^{*}$. We have $\mathrm{I} 1+\mathrm{j} I 2=(\mathrm{P}-\mathrm{j} \mathrm{Q}) / \mathrm{V}$, since $\mathrm{E} L \delta^{\prime}=\mathrm{V}+\mathrm{j} \mathrm{Xd}^{\prime} \mathrm{I}$. We compute [20],

$$
\mathrm{E}\left\llcorner\delta^{\prime}=(\mathrm{V}+\mathrm{QXd} / \mathrm{V})+\mathrm{j}(\mathrm{PXd} / \mathrm{V})\right.
$$

The initial generator angle $\delta 0$ is then obtained by adding the pre-transient voltage angle $\alpha$ to $\delta$, or $\delta 0=\delta^{\prime}+\alpha$.

d) The Ybus matrix for each network condition is calculated.

e) Finally, we eliminate all the nodes except for the internal generator nodes, and obtain the Ybus matrix for the reduced network. The reduction can be achieved by matrix operation, all the nodes have zero injection currents except for the internal generator nodes. This property is used to obtain the network reduction, and is explained below,

$$
\mathrm{I}=\mathrm{YV}
$$

$\mathrm{Y}$ and $\mathrm{V}$ matrices are partitioned accordingly. $\mathrm{Vn}$ has the dimension $(\mathrm{n} * 1), \mathrm{Vr}$ has the dimension ( $\left.\mathrm{r}^{*} 1\right)$. Expanding the above matrix,

$$
\begin{aligned}
& \mathrm{In}=\mathrm{YnnVn}+\mathrm{YnrVr} \\
& 0=Y r n V n+Y r r V r
\end{aligned}
$$

Where the subscript ' $n$ ' is used to represent the generator nodes, and the subscript ' $r$ ' is used for the remaining nodes. From which, we eliminate V, to find

$$
\mathrm{In}=(\text { Ynn-YnrYrr-1Yrn)Vn }
$$

The matrix $\left(Y_{n n}-Y_{n r} Y_{r r}^{-1} Y_{r n}\right)$ is the desired reduced matrix $Y$. It has the dimensions ( $n^{*} n$ ). The network reduction illustrated by the above equations is a convenient analytical technique that can be used only when the loads are treated as constant impedances. If the loads are not considered to be constant impedances, the identity of the load buses must be retained. Network reduction can be applied only to those nodes that have zero injection current.

\subsection{Variable series compensation}

It is recognized that the series reactive impedance of the line primarily limited ac power transmission over long lines. With the Flexible AC transmission system (FACTS) technology, it has been demonstrated that variable series compensation is highly effective in both controlling power flow in the line and in improving stability. Series capacitors have been successfully used for many years in order to enhance the stability and loadability of high voltage transmission networks. The principle is to compensate the inductive voltage drop in the line by an inserted capacitive voltage or to reduce the effective reactance of the 
transmission line. The inserted voltage provided by a series capacitor is in proportion to and in quadrature with the line current. Thus, the generated reactive power provided by the capacitor has a self-regulating impact. The objectives of series compensation are voltage stability, improvement of transient stability, power oscillation damping, and sub-synchronous oscillation damping.

\subsection{Thyristor controlled series capacitor (TCSC)}

TCSC consists of the series compensating capacitor shunted by a Thyristor Controlled Reactor (TCR) as shown in Figure 1. In a practical TCSC implementation, several such basic compensators may be connected in series to obtain the desired voltage rating and operating characteristics [21].

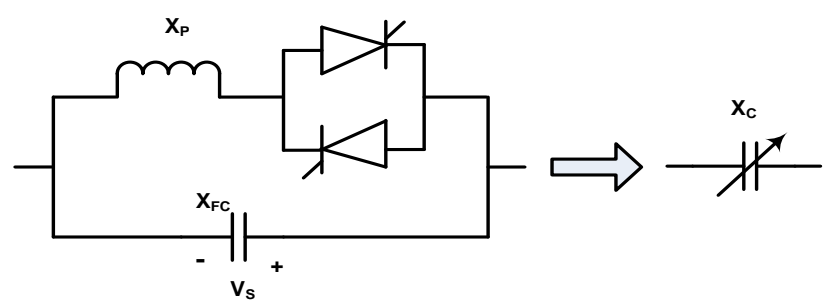

Figure 1. Schematic diagram of TCSC

This arrangement is similar in structure to the Thyristor Switched Series Capacitor (TSSC), and if the impedance of the reactor (XL) is sufficiently smaller than that of the capacitor (XC), then it can be operated in an ON/OFF manner like the TSSC. However, the basic idea behind the TCSC scheme is to provide a continuously variable capacitor by means of partially canceling the effective compensating capacitance by the TCR. TCR at the fundamental system frequency is a continuously variable reactive impedance, controllable by delay angle $\alpha$, the steady state impedance of the TCSC is that of a parallel LC circuit, consisting of a fixed capacitive impedance $(\mathrm{Xc})$, and a variable inductive impedance, XL $(\alpha)$, that is.

$$
X_{T C S C}(\alpha)=\frac{X_{L} X_{C}}{X_{L}(\alpha)-X_{C}}
$$

Where $\mathrm{XL}(\alpha)=\mathrm{XL} * \pi /(\pi-2 \alpha-\sin \alpha), \mathrm{XL} \leq \mathrm{XL}(\alpha) \leq \infty, \mathrm{XL}=\omega \mathrm{L}$. TCSC presents a tunable parallel LC circuit to the line current that is substantially a constant alternating current source. As the impedance of the controlled reactor $(\mathrm{XL}(\alpha))$ is varied from its maximum (infinity) toward its minimum $(\omega \mathrm{L})$, the TCSC increases its minimum capacitive impedance, $\mathrm{XTCSCmin}=\mathrm{Xc}=1 / \omega \mathrm{C}$, (and thereby the degree of series capacitive compensation) until parallel resonance at $\mathrm{Xc}=\mathrm{XL}(\alpha)$ is established, and XTCSCmax theoretically becomes infinite.

\section{MODELING OF TCSC}

The overall reactance XC of the TCSC [2] is given in terms of the firing angle $\alpha$ as [22],

$$
X_{C}=\beta_{1}\left(X_{F C}+\beta_{2}\right)-\beta_{4} \beta_{5}-X_{F C}
$$

Where $\beta_{1}=\frac{2(\pi-\alpha)+\sin 2(\pi-\alpha)}{\pi}, \beta_{2}=\frac{X_{F C} X_{P}}{X_{F C}-X_{P}}, \beta_{3}=\sqrt{\frac{X_{F C}}{X_{P}}}, \beta_{4}=\beta_{3} \tan \left[\beta_{3}(\pi-\alpha)\right]-\tan (\pi-\alpha)$ and $\beta_{5}=\frac{4 \beta_{2}^{2} \cos ^{2}(\pi-\alpha)}{\pi X_{P}}$

In this paper, it is considered that the TCSC is operated only in the capacitive mode. The capacitive reactance (XFC) of the TCSC is chosen as half of the reactance of the line in which the TCSC is placed, and the TCR reactance (XP) is chosen to be $1 / 3$ of XFC.

In the next step, a controller is employed along with the TCSC. The block diagram of the control scheme used is shown in Figure 2. 


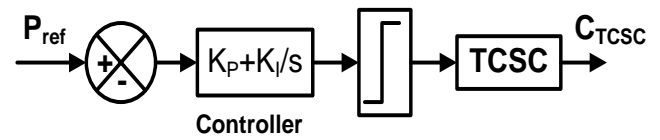

Figure 2. Block diagram of control scheme

The active power flow (P) through the line containing TCSC is taken as the control variable. It is compared with the reference value of active power flow (Pref), and the error is fed to a Proportional Integral (PI) controller. The output of the PI is the firing angle of the TCSC ( $\alpha$ ). This $\alpha$ is passed through a limiter to keep it within the capacitive operation zone of the TCSC (between $145^{\circ}$ and $180^{\circ}$ ). The output of the limiter is supplied to the firing circuit of TCSC. The capacitance of TCSC (CTCSC) is included in the line dynamics.

\section{TRAJECTORY SENSITIVITY ANALYSIS}

Multi-machine power system is represented by a set of differential equations,

$$
\dot{x}=f(t, x, \lambda), x\left(t_{0}\right)=x_{0}
$$

The sensitivities of state trajectories with respect to system parameters can be found by perturbing $\lambda$ from its nominal value $\lambda_{0}$. The equations of trajectory sensitivity [2] are,

$$
\dot{x_{\lambda}}=\left[\frac{d f}{d x}\right] x_{\lambda}+\left[\frac{d f}{d \lambda}\right], x_{\lambda}\left(t_{0}\right)=0
$$

Where $x_{\lambda}=\partial x / \partial \lambda$. The sensitivities can be found in a simpler way by using the numerical method.

\subsection{Quantification of trajectory sensitivity (TS) and its implication}

Trajectory sensitivities $\left(\partial \delta_{i j} / \partial \lambda\right)$ and $\left(\partial \Delta \omega_{r i} / \partial \lambda\right)$ gives the information about the effect of change of parameter on individual state variables, and hence on the generators of the system. However, to know the overall system condition, we need to sum up all these information. The norm of the sensitivities of $\delta_{i j}$ and $\Delta \omega_{r i}$ are calculated. The sensitivity norm for m machine system is given by,

$$
S_{N}=\sqrt{\sum_{i=1}^{m}\left[\left(\frac{\partial \delta_{i j}}{\partial \lambda}\right)^{2}+\left(\frac{\partial \Delta \omega_{r i}}{\partial \lambda}\right)^{2}\right]}
$$

A new term $\eta$ (ETA) is defined as the inverse of the maximum of $\mathrm{SN}$, i.e., $\eta=1 / \max \left(S_{N}\right)$. As the system moves towards instability, the oscillation in trajectory sensitivity (TS) will be more resulting in larger values of SN. This will result in the smaller values of $\eta$. Ideally, $\eta$ should be zero at the point of instability. Therefore, the value of $\eta$ gives us an indication of distance from instability. In this paper, $\eta$ is used for assessing the relative stability conditions of the system with different values of fault clearing time, system load and firing angle of TCSC.

\section{RESULTS AND DISCUSSION}

In this paper, WSCC 3 machine nine-bus system [22] is considered to show the effectiveness of the proposed approach. A three-phase fault is simulated in one of the lines of the nine-bus system. The simulation is done in three steps. To start with, the pre-fault system is run for a small time. Then, a symmetrical fault is applied at one end of the line. Simulation of the faulted condition continues till the fault is cleared after a time tcl. Then, the post-fault system is simulated for a longer time (say $5 \mathrm{sec}$ ) to observe the nature of the transients. The fault may be of self-clearing type (i.e., isolation of line is not required for fault clearance) or may be cleared by isolating the faulted line. Table 1 presents the normalized values of eta $(\eta)$ for the nine bus test system with TCSC placed in different fault locations. 
Table 1. Normalized $\eta$ (ETA) Values of 9 Bus System for TCSC Placed in Different Fault Locations

\begin{tabular}{cccccccc}
\hline Fault at bus & Line Isolated & Line 4-5 & Line 5-7 & Line 4-6 & Line 6-9 & Line 7-8 & Line 8-9 \\
\hline 5 & $4-5$ & --- & 1.222 & 1.015 & 1.141 & 0.995 & 1.030 \\
5 & $5-7$ & 0.978 & --- & 1.064 & 1.117 & 0.993 & 1.057 \\
6 & $4-6$ & 0.982 & 0.920 & --- & 1.447 & 1.004 & 1.013 \\
6 & $6-9$ & 1.000 & 0.968 & 0.901 & --- & 1.019 & 0.927 \\
8 & $7-8$ & 1.027 & 1.034 & 0.966 & 1.000 & --- & 0.946 \\
8 & $8-9$ & 1.139 & 1.083 & 0.993 & 0.979 & 0.951 & --- \\
\hline
\end{tabular}

Here, trajectory sensitivity method is used to find the location, which improves the stability margin to maximum. Figure 3 presents the characteristics of relative rotor angle for the fault at 7 th bus, line 5-7 is opened with fault clearing time of $0.0873 \mathrm{sec}$, whereas with $50 \%$ compensation has been depicted in Figure 4 .

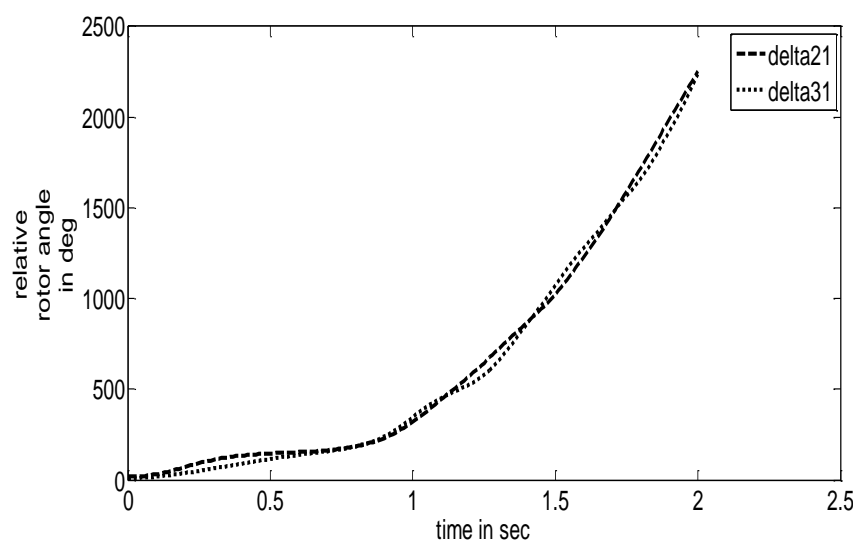

Figure 3. Fault at $7^{\text {th }}$ bus, line 5-7 is opened. Clearing time $0.0873 \mathrm{Sec}$

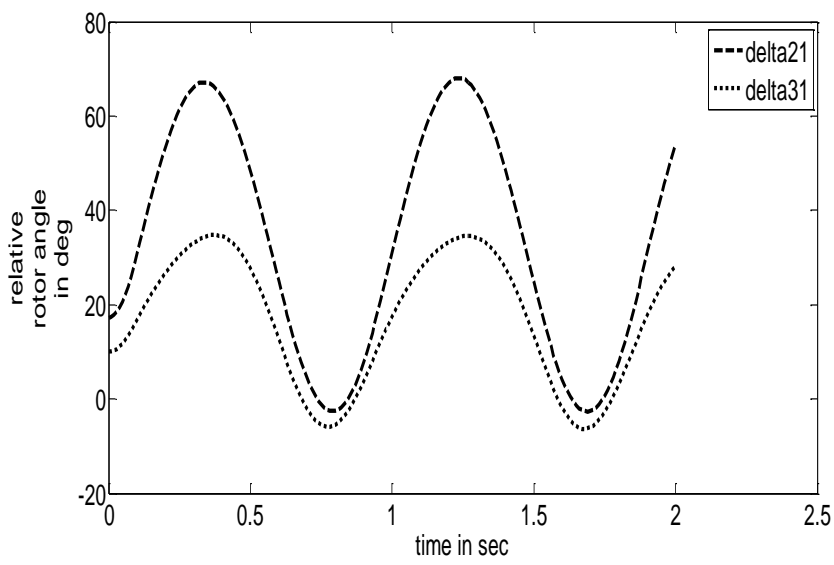

Figure 4. Fault at $7^{\text {th }}$ bus, line 5-7 is opened. Clearing time is $0.0873 \mathrm{Sec}$, with $50 \%$ compensation

When TCSCS is placed in line 6-9, the relative rotor angle is depicted in Figure 5, which represents the improved transient stability of the system. Figure 6 depicts the relative rotor angle for the fault at 7 th bus, line 5-7 is opened and the fault clearing time is $0.18 \mathrm{sec}$. The relative rotor angle for the fault at 7 th bus, line 5-7 is opened with the fault clearing time of $0.22 \mathrm{sec}$ and $50 \%$ fixed compensation is depicted in Figure 7. 


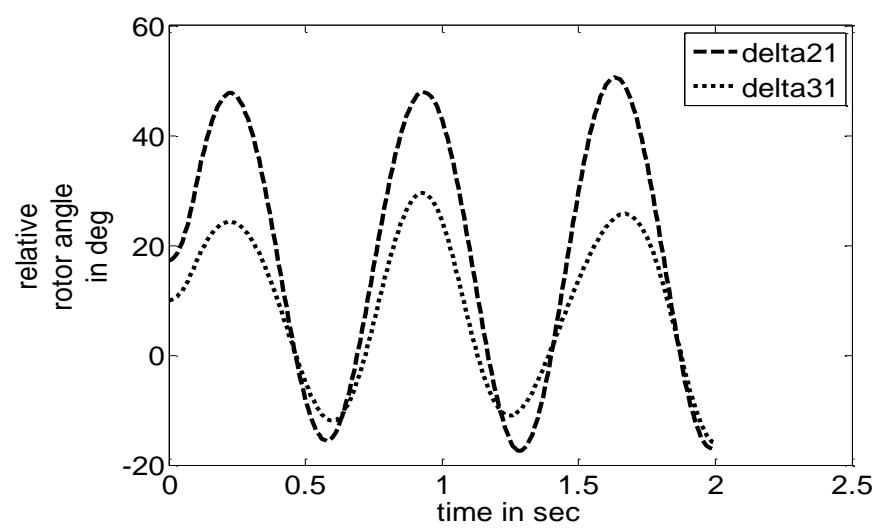

Figure 5. Fault at $7^{\text {th }}$ bus, line $5-7$ is opened. Clearing time is $0.0873 \mathrm{sec}$ with $\mathrm{Kp}=0.8, \mathrm{Ki}=9$. TCSC is placed in line 6-9

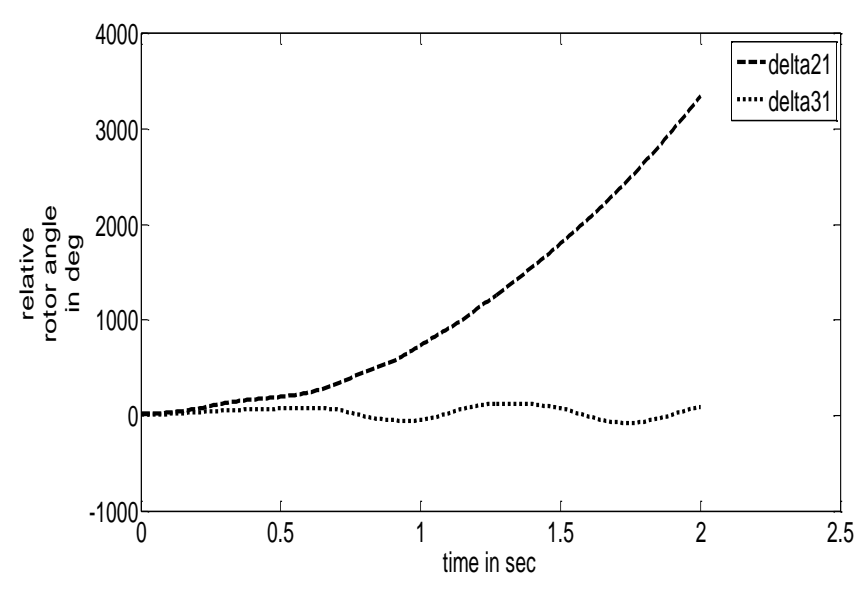

Figure 6 . Fault at $7^{\text {th }}$ bus, line $5-7$ is opened. Clearing time is $0.18 \mathrm{Sec}$

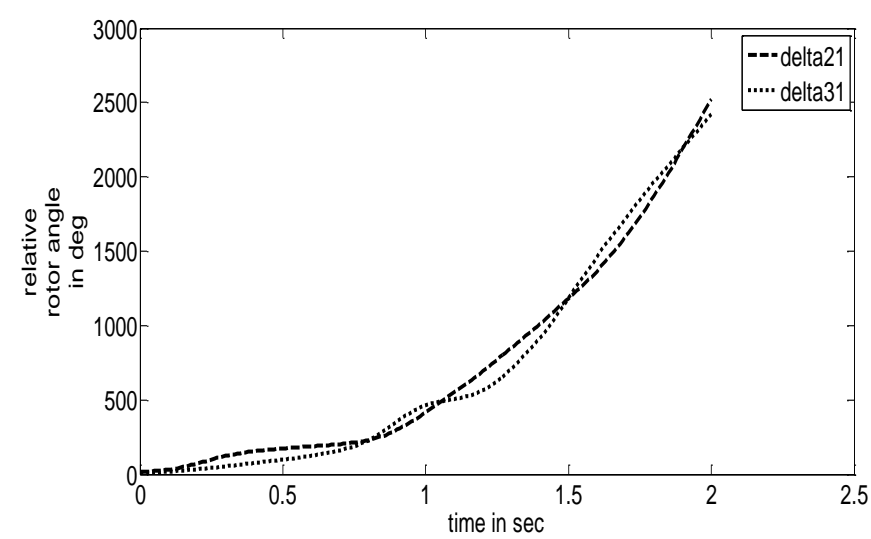

Figure 7. Fault at $7^{\text {th }}$ bus, line 5-7 is opened. Clearing time is $0.22 \mathrm{Sec}$ with $50 \%$ fixed compensation

TCSC causes improvement of system stability condition the most, when it is placed in line 6-9 or line 5-7. Therefore, we shall study the effect of TCSC (along with controller) in these two locations. Another interesting issue is the comparison between the effects of TCSC controller, and the TCSC used in open loop, i.e., without a controller. In open loop, the TCSC acts as a fixed capacitor throughout the period of 
disturbance, and it is the fixed capacitor mode of operation. The effects of this fixed capacitor and the effects of a TCSC controller combination (with suitably chosen controller constants) on the transient stability condition are investigated and compared here.

From the above simulation studies, it can be concluded that the improvement in the transient stability condition of the system is much more with the TCSC controller combination. These results highlight the effectiveness of the application of TCSC along with a controller in improving the transient stability of a power system.

\section{CONCLUSIONS}

This paper presents the improvements of transient stability using TCSC. Accurate analysis of the transient stability requires the detailed modeling of generating units, and other equipments. In this paper, the transient stability assessment of WSCC-9 bus system is done for different cases such as faults of self clearing type, fault cleared by line removal, etc. The damping of the system is incorporated, and the analysis gives the better results. The case studies depicts the optimal location of fixed compensation in the WSCC 9 bus system as line 6-9, based on the first swing peak value reduction. The TCSC controller has been modeled and implemented on the WSCC 9 bus system at the optimal location. The results highlight the effectiveness of the application of the TCSC in improving the transient stability of power system.

\section{ACKNOWLEDGMENTS}

This research work has been carried out based on the support of "Woosong University's Academic Research Funding - 2018",

\section{REFERENCES}

[1] Kundur P, Paserba J, "Definition and Classification of Power System Stability," IEEE Transactions on Power Systems, 2004; 19(2): 1387-1401.

[2] Chatterjee D, Ghosh A, "TCSC control design for transient stability improvement of a multi-machine power system using trajectory sensitivity," Electric Power Systems Research, 2007; 77: 470-483.

[3] Kumar PS, "Transient Stability Enhancement of Power System Using TCSC," International Journal of Electrical and Computer Engineering, 2012; 2(3): 317-324.

[4] Rosso D, Canizares CA, Dona VM, "A study of TCSC controller design for power system stability improvement," IEEE Transactions on Power Systems, 2003; 18(4): 1487-1496.

[5] Shankar R, Srivastava J, "Transient Stability Study by Using Thyristor Controlled Series Compensator Controller for Single Machine Infinite Bus (SMIB) System," International Journal of Engineering Science and Innovative Technology, 2013; 2(5): 30-34.

[6] Kumkratug P, "The Effect of Thyristor Controlled Series Capacitor on Transient Stability of Single Machine Infinite Bus System with the Exact Short Transmission Line Model," American Journal of Applied Sciences, 2012; 9(3): 425-428.

[7] Srinivasa Rao G, Srujana A, "Transient Stability Improvement of Multi-machine Power System Using Fuzzy Controlled TCSC," International Journal of Advancements in Research \& Technology, 2012; 1(2): 162-172.

[8] Nascimento S, Gouvêa Jr MM, "Voltage Stability Enhancement in Power Systems with Automatic Facts Device Allocation," Energy Procedia, 2017; 107: 60-67.

[9] Esmaili M, Shayanfar HA, Moslemi R, "Locating series FACTS devices for multi-objective congestion management improving voltage and transient stability," European Journal of Operational Research, 2014; 236(2): 763-773.

[10] Bakhshi M, Holakooie MH, Rabiee A, "Fuzzy based damping controller for TCSC using local measurements to enhance transient stability of power systems," International Journal of Electrical Power \& Energy Systems, 2017; 85: $12-21$.

[11] Colvara LD, Araujo SCB, Festraits EB, "Stability analysis of power system including facts (TCSC) effects by direct method approach," International Journal of Electrical Power \& Energy Systems, 2005; 27(4): 264-274.

[12] Rautray SK, Choudhury S, Mishra S, Rout PK, "A Particle Swarm Optimization based Approach for Power System Transient Stability Enhancement with TCSC," Procedia Technology, 2012; 6: 31-38.

[13] Kolcun M, Čonka Z, Beňa L, Kanálik M, Medve D, "Improvement of Transmission Capacity by FACTS devices in Central East Europe power system," IFAC-PapersOnLine, 2016; 49(27): 376-381.

[14] Roselyn JP, Devaraj D, Dash SS, "Multi-Objective Genetic Algorithm for voltage stability enhancement using rescheduling and FACTS devices," Ain Shams Engineering Journal, 2014; 5(3): 789-801.

[15] Gasperic S, Mihalic R, "The impact of serial controllable FACTS devices on voltage stability," International Journal of Electrical Power \& Energy Systems, 2015; 64: 1040-1048.

[16] Reddy SS, "Optimal Placement of FACTS Controllers for Congestion Management in the Deregulated Power System," International Journal of Electrical and Computer Engineering (IJECE), 2018; 8(3): 1336-1344. 
[17] Tripathi A, Rao KU, Venkatesha L, "Multi-Machine Stability Using Dynamic Inversion Technique," International Journal of Electrical and Computer Engineering (IJECE), 2017; 7(6): 3176-3189.

[18] Wartana IM, Agustini NP, Singh JG, "Optimal Integration of the Renewable Energy to the Grid by Considering Small Signal Stability Constraint," International Journal of Electrical and Computer Engineering (IJECE), 2017; 7(5): 2329-2337.

[19] Reddy SS, "Congestion Management and Voltage Profile Improvement in a Hybrid Power System with FACTS Controllers," International Journal of Applied Engineering Research, 2017; 12(9): 1195-1203.

[20] Acevedo LF, Bothia-Vargas G, Candelo JE, "Dynamic Voltage Stability Comparison of Thermal and Wind Power Generation with Different Static and Dynamic Load Models," International Journal of Electrical and Computer Engineering (IJECE), 2018; 8(3): 1401-1411.

[21] Oukennou A, Sandali A, Elmoumen S, "Coordinated Placement and Setting of FACTS in Electrical Network based on Kalai-smorodinsky Bargaining Solution and Voltage Deviation Index," International Journal of Electrical and Computer Engineering (IJECE), 2018; 8(6): 4079-4088.

[22] Anderson PM, Foud AA, "Power System Control and Stability," Iowa State University Press, Ames, Iowa, 1977. 